Dossiê Especial: Experiências do PIBID na formação inicial e continuada de professores de

línguas estrangeiras

HIBARINO \& NODARI (orgs)

Revista X, vol.1, 2015

\title{
PERSPECTIVA DIFERENCIADA NAS AULAS DE INGLÊS EM ESCOLA PÚBLICA - O PROJETO CALEIDOSCÓPIO
}

Alternative perspective of English teaching in a public school - the kaleidoscope project

\author{
Tatiana Caniceiro MILÉO ${ }^{1}$ \\ Adriana da ROSA ${ }^{2}$ \\ Gislaine Ortiz dos SANTOS $^{3}$
}

\begin{abstract}
Resumo: Este artigo tem como objetivo relatar a aplicação de uma abordagem alternativa, através do projeto Caleidoscópio, elaborada para a disciplina de Língua Inglesa para uma turma de $6^{\circ}$ ano do Colégio Professor Algacyr Munhoz Maeder, por bolsistas do PIBID - Inglês da UFPR. O PIBID, Programa Institucional de bolsas de iniciação à docência, disponibilizado pela UFPR, prioriza a parceria com escolas públicas estaduais cujo IDEB (Índice de Desenvolvimento da Educação Básica) esteja abaixo de 5, resultado este obtido através da Prova Brasil. O projeto Caleidoscópio contou com contribuições teóricas de PACHECO (2012) e JORDÃO (2007) que fornecem outra perspectiva de ver o processo de ensino - aprendizagem, mais especificamente de Língua Inglesa no contexto de escola pública. As integrantes do PIBID buscaram levar para a sala de aula atividades e formas de trabalhar com os alunos baseadas nos quatro pilares da Escola da Ponte, a saber: autonomia, solidariedade, cooperação e democraticidade. A parceria entre PIBID e escola pública permitiu a ampliação da visão sobre ensino de Língua Estrangeira em contexto de escola pública, além de intensificar a formação inicial docente das bolsistas envolvidos.
\end{abstract}

Palavras-chave: Ensino de Língua Inglesa; PIBID - Inglês; Escola da Ponte; abordagem alternativa.

\begin{abstract}
This article aims to describe how an English teaching alternative approach called Kaleidoscope was developed in a $6^{\mathbf{a}}$ grade English class at Colégio Professor Algacyr Munhoz Maeder, by scholarship students from PIBID - English UFPR. PIBID (Programa Institucional de Bolsa de Iniciação à Docência) offered by UFPR prioritizes partnerships with public schools which IDEB (Índice de Desenvolvimento da Educação Básica) is lower than 5, which result is obtained by Prova Brasil. The Kaleidoscope project relied on theoretical contributions as PACHECO (2012) and JORDÃO (2007) who offered a different perspective on teaching and learning process, specifically in an English teaching context in a public school. The members of PIBID tried to achieve in the classroom activities and different ways of working with the students based on the four pillars of "Escola da Ponte", which are: autonomy, solidarity, cooperation and democracy. Partnership between PIBID and public school made it possible to broaden the perspective of foreign language teaching in a public school context, besides improving the inicial teacher training of the members involved.
\end{abstract}

Keywords: English Language Teaching; PIBID - English; Escola da Ponte; alternative approach.

\footnotetext{
${ }^{1}$ Graduanda em Letras pela Universidade Federal do Paraná. taticmileo@gmail.com.

${ }^{2}$ Graduanda em Letras pela Universidade Federal do Paraná. arosapink@ hotmail.com.

${ }^{3}$ Graduada em Letras na Universidade Federal do Paraná. gisortizs@gmail.com.
} 


\section{Dossiê Especial: Experiências do PIBID na formação inicial e continuada de professores de línguas estrangeiras \\ HIBARINO \& NODARI (orgs) \\ Revista X, vol.1, 2015}

\section{Introdução}

Há diferentes formas de olhar para o processo de ensino e aprendizagem de Língua Inglesa. Entendendo essa ação como parte integrante da formação de bolsistas de um projeto de iniciação à docência, desenvolvemos o projeto Caleidoscópio, em uma turma de $6^{\circ}$ ano de escola pública, objetivando levar para a sala de aula uma perspectiva diferenciada para o ensino de Língua Inglesa. A escola, localizada no Bairro Alto - Curitiba, foi escolhida por fazer parte do Programa Institucional de Bolsa de Iniciação a Docência (PIBID).

Ao iniciarmos as observações das aulas de Língua Inglesa percebemos que em um dos $6^{\circ}$ anos o trabalho do professor era dificultado pelo grande número de alunos com comportamento agitado e pela falta de tempo para que o professor pudesse dar atenção de forma individualizada. Com esta turma em mente, buscamos uma forma alternativa de trabalhar a Língua Inglesa. Para isso, escolhemos como base teórica o projeto "Fazer a Ponte" de José Pacheco (2012) e seguimos os quatro pilares importantes da Escola da Ponte: autonomia, solidariedade, democraticidade e cooperação para a nossa prática em sala de aula. Entendemos que aprender uma língua estrangeira, assim como outras áreas do conhecimento, diz muito mais respeito a desenvolver potencialidades do que apreender conteúdos. Nesse sentido, levamos em consideração que a língua inglesa seria instrumento para o desenvolvimento de outras potencialidades, tal como propõe Howard Gardner (1993) em sua teoria sobre as múltiplas inteligências, priorizando as diferentes formas de aprender do aluno.

Também seguimos como fundamentação teórica as contribuições da pesquisadora Clarissa Jordão (2007) sobre o letramento crítico e a discussão que esta faz de diferentes visões sobre a realidade, o uso da língua como espaço de construção de sentido para a sala de aula, e o conflito como algo positivo.

Ao escolher o nosso embasamento teórico, procuramos também olhar para o processo de ensino-aprendizagem de uma outra perspectiva. Por isso, os membros do PIBID - Inglês nomearam o projeto de "Caleidoscópio": um objeto através do qual você olha uma imagem que pode ser vista de diferentes formas. Assim, o nome do projeto refletia um dos objetivos principais, o qual era mudarmos as "lentes" com que víamos o ensino e aprendizado de Língua Inglesa para também mudarmos nossas práticas e, consequentemente, os resultados.

Este artigo está organizado em 4 partes. Na Introdução, faremos uma breve contextualização do projeto Caleidoscópio. Na Fundamentação Teórica relataremos como cada teórico, mencionado acima, contribuiu para o ensino de Língua Inglesa durante o 
Dossiê Especial: Experiências do PIBID na formação inicial e continuada de professores de línguas estrangeiras

HIBARINO \& NODARI (orgs)

Revista X, vol.1, 2015

projeto. A terceira parte será dedicada ao relato do desenvolvimento do projeto e a última parte, para as considerações finais.

\section{Fundamentação teórica}

\section{Letramento Crítico}

Segundo a pesquisadora Clarissa Jordão (2007), desde que a língua passou a ser concebida como discurso por alguns pós-estruturalistas como Foucault e Derrida, ou seja, concebida como sistema de construção de sentidos ao invés de código de identificação e transcrição de sinais linguísticos exteriores a ela, mudanças profundas têm ocorrido. No mundo atual, contemporâneo e globalizado coloca-se a interculturalidade e o ensino/aprendizagem de línguas num espaço diferenciado, no qual comunicar-se passa pelo uso de uma língua, seja ela estrangeira ou materna, e pela consciência da própria cultura e da cultura do outro. Os discursos estão assim, sujeitos às práticas sociais, ao mesmo tempo em que as sujeitam, ou ainda, constroem sentidos e são construídos por eles.

Nesse contexto, os sujeitos críticos devem ser capazes de examinar as informações e as implicações das diferentes formas de pensar e agir. Pressupor realidades construídas culturalmente nas relações que estabelecem entre diferentes visões de mundo, implicando em uma concepção de criticidade específica. O local e o global se afetam mutuamente, e as antigas certezas são abaladas pelas constantes mudanças nos rumos das sociedades e das ciências. Essa instabilidade possibilitada pela intercomunicação rápida entre diferentes culturas (intra e inter-nacionais) pode exercer efeito bastante produtivo se entendermos a positividade dos confrontos entre perspectivas e percebermos a aprendizagem como um embate constante entre diferentes visões de mundo.

O letramento crítico, então, apresenta-se como uma alternativa para ressaltar aos nossos olhos a multiplicidade de maneiras de construir sentidos e entender o mundo, as relações de poder que se estabelecem entre elas, a produtividade dos confrontos decorrentes de tais relações, e a necessidade de especular sobre o que possibilita a existência de cada uma das perspectivas, bem como quais podem ser suas consequências no mundo. No século XXI, esses mundos são cada vez mais influenciados e tornados possíveis pela virtualidade, que contribui para determinar os sentidos que podemos construir. O mundo digital afeta nossos procedimentos interpretativos, mesmo quando não fazemos contato direto com computadores, com a internet, com o mundo virtual, porque as formas de comunicação possíveis são 
Dossiê Especial: Experiências do PIBID na formação inicial e continuada de professores de línguas estrangeiras

HIBARINO \& NODARI (orgs)

Revista X, vol.1, 2015

expandidas e o processo comunicativo em geral se reconfigura a partir das possibilidades que a virtualidade e a simultaneidade apresentam.

A linguagem verbal, especialmente a escrita, já não é mais o único nem o principal meio disponível para construirmos sentidos válidos. Podemos lançar mão de múltiplos recursos, que incluem a linguagem escrita, mas não se limitam a ela. A linguagem visual e a auditiva, por exemplo, assim como a interatividade do hipertexto e a multimodalidade de websites abrem uma gama enorme de procedimentos interpretativos que influenciam nossas maneiras de construir sentidos, mesmo junto às camadas da população global que ainda vivem supostamente à margem das sociedades digitais em vários países. Ou ainda, "a virtualidade (que não é o contrário de realidade, mas sim uma forma específica de construir realidades possíveis) afeta nossos modos de fazer sentidos, nossas maneiras de interpretar o mundo" (JORDÃO, 2007, p. 25). Levar o sujeito a construir sentidos, sendo capaz de elaborar entendimentos sobre o que possibilita a construção de certos pontos de vista e suas implicações para a vida do sujeito e do planeta é estar em processo de letramento crítico. Aprender e ensinar uma língua estrangeira, portanto, aparece nessa perspectiva como elemento extremamente importante na formação dos cidadãos.

\section{Escola da Ponte}

A Escola da Ponte, localizada em Portugal (Vila das Aves) e idealizada pelo educador José Pacheco, contribui para as pesquisas e prática na área da Educação ao trazer uma nova perspectiva sobre ensino e aprendizagem, a qual se baseia nos seguintes pilares: autonomia, solidariedade, democraticidade e responsabilidade. Para uma melhor ação educativa, os princípios não valem somente para alunos e professores, mas também para pais, funcionários da escola e outros envolvidos, já que o projeto "Fazer a Ponte" tem como finalidade formar cidadãos mais responsáveis, autônomos e envolvidos socialmente em sua comunidade sempre pensando no coletivo, tanto aquele envolvido no ambiente escolar como fora dele também.

Outro diferencial da Escola da Ponte é que ao considerar cada aluno como único, o projeto aborda o processo de aprendizagem de cada um de forma diferenciada. Prioriza-se o desenvolvimento de identidade pessoal baseando nos valores da iniciativa, criatividade e responsabilidade, fazendo com que o aluno tenha, cada vez mais, um autoconhecimento mais aprofundado e um relacionamento mais solidário com os outros. Para que isso ocorra, os alunos participam das decisões tomadas no ambiente escolar, sendo responsáveis pelo seu próprio desenvolvimento e do coletivo ao mesmo tempo. 


\section{Dossiê Especial: Experiências do PIBID na formação inicial e continuada de professores de línguas estrangeiras \\ HIBARINO \& NODARI (orgs) \\ Revista X, vol.1, 2015}

O papel do professor, de acordo com o projeto "Fazer a Ponte", também é diferente.

Sendo o educador um facilitador do conhecimento e não detentor único dele, o professor se torna uma ponte entre o aluno e o conhecimento a ser adquirido, habilidades a serem desenvolvidas e diversas experiências a serem vivenciadas, o que contribuirá para a formação de todos os envolvidos como cidadãos. Entretanto, essa "ponte" sempre leva em consideração a cultura, o conhecimento de mundo do aluno e as experiências que ele traz à escola.

\section{Inovação no ensino e aprendizagem}

As Diretrizes Estaduais da Educação Básica do Estado do Paraná para Línguas Estrangeiras Modernas estão baseadas numa visão dialógica da linguagem. Em outras palavras: “[...].a língua concebida como discurso, não como estrutura ou código a ser decifrado, constrói significados e não apenas os transmite”. (DCE-PR, 2008. p. 53).

A proposta adotada nas DCE-PR se baseia na corrente sociológica e nas teorias do Círculo de Bakhtin, que concebem a língua como discurso. Segundo Faraco (2003), essa visão na maneira de ensinar foi a superação de certos valores objetivos que eram atribuídos ao ensino de língua estrangeira até então. A língua passou a ser vista como dotada de significados subjetivos, tanto a nível individual quanto coletivo. A língua é complexa e singular, e para que exista, precisa estar imersa em uma interação entre sujeitos, pois é intrínseco que cada um traga embutida nela sua bagagem de experiências pessoais e sua visão de mundo. Diante disso a linguagem serve como um meio para o conhecimento do outro e de si mesmo.

Para que seja possível reconhecer esse papel que a língua exerce no desenvolvimento cognitivo do aluno, o professor precisa se perguntar constantemente o que tem feito para que o diálogo e a construção de sentidos esteja efetivamente ocorrendo. Conforme Hilário Bohn:

O objeto pronto, acabado, estruturado é substituído pelo movimento, pelo inacabado, por movimentos estruturantes.[...] $\mathrm{O}$ definitivo perde a sua estabilidade dentro de uma perspectiva de realidade cósmica de uma ecologia em construção. Inacabada. Há convergências, mas não certezas. Constroem-se consensos sociais, mas os participantes têm consciência da instabilidade de tais consensos estabelecidos através das conversações ou pelos agires comunicativos. (BOHN, 2003, p. 117).

Diante dessa consciência do inacabado, as aulas precisam ser destituídas do caráter autoritário, de verdades pré-concebidas. Essa postura coloca o professor na posição de constante aprendiz, pois verdades irão mudar a depender da interação que se coloca em cada 


\section{Dossiê Especial: Experiências do PIBID na formação inicial e continuada de professores de línguas estrangeiras \\ HIBARINO \& NODARI (orgs) \\ Revista X, vol.1, 2015}

ocasião. Isso traria uma emoção caracterizada pela constante inovação. Ainda conforme Bohn:

O que permite a inovação permanente? A descida diária do professor para a linguagem dialógica. O compromisso de que a chegada do dia anterior não permite estabelecer o definitivo.[...] O consenso construído no dia anterior não permite estabelecer a verdade dogmática, mas deve ser motivação do contínuo reestruturar. (BOHN, 2003 p. 121).

O projeto que será apresentado na sequência reflete a experimentação de um novo modelo que buscou, dentre outros objetivos, contemplar alguns aspectos dessa inovação possibilitada através da busca pela polifonia, ou seja, pela multiplicidade de vozes dos envolvidos no processo de aprendizagem de uma língua estrangeira.

\section{Desenvolvimento do projeto}

Quando o ano letivo de 2013 iniciou, tivemos a oportunidade de observar algumas aulas e propor algumas atividades em uma das escolas afiliadas ao PIBID - Inglês. Nós três sentimos que precisávamos ousar mergulhando em alguma perspectiva diferenciada que trouxesse maior abertura para a expressão individual de cada aluno durante as aulas. Conforme Bohn, "[o] professor precisa aproximar-se de seu aluno e o aluno precisa aproximar-se de seu professor e de seus colegas de sala de aula. A linguagem dialógica exige esta aproximação” (BOHN, 2003, p, 121). Já Pacheco (2012), defende que:

[t]odo o conhecimento verdadeiramente significativo é autoconhecimento, pelo que se impõe que seja construído pela própria pessoa a partir da experiência. A aprendizagem é um processo social em que os alunos, heuristicamente, constroem significados a partir da experiência. (PACHECO, 2012, p, 154).

E continua argumentando que

[...] os objetivos de aprendizagem não são uma coisa "secreta", oculta para os alunos, que somente o professor conhece. Os objetivos são o ponto de partida da aprendizagem. A coisa começa com a criança escolhendo objetivos, a partir de uma lista de objetivos de uma disciplina. (PACHECO, 2012, p. 20).

Inspiradas por essa abordagem, sugerimos um projeto no qual os alunos teriam a possibilidade de escolher a ordem em que aprenderiam o conteúdo anual proposto para língua inglesa, e então desenvolvessem autonomia para buscar o material necessário para a própria 


\section{Dossiê Especial: Experiências do PIBID na formação inicial e continuada de professores de línguas estrangeiras \\ HIBARINO \& NODARI (orgs) \\ Revista X, vol.1, 2015}

aprendizagem. Idealizamos que dessa forma eles experimentariam mais liberdade de expressão, podendo se manifestar verbalmente ou levantar e conversar com os colegas sobre suas dúvidas ou comentários a qualquer momento da aula. Deveríamos nos certificar, entretanto, que os alunos levariam suas pesquisas adiante, aprendendo o conteúdo escolhido, com responsabilidade. Estas crenças encontraram eco na proposta da Escola da Ponte, conforme esta foi idealizada por José Pacheco (2012):

A intencionalidade educativa que serve de referencial ao projeto Fazer a Ponte orienta-se no sentido da formação de pessoas e cidadãos cada vez mais cultos, autônomos, responsáveis e solidários e democraticamente comprometidos na construção de um destino coletivo e de um projeto de sociedade que potenciem a afirmação das mais nobres e elevadas qualidades de cada ser humano. (PACHECO, 2012, p. 151).

Além disso, de acordo com os pressupostos da Escola da Ponte, "na sua dupla dimensão individual e social, o percurso educativo de cada aluno supõe um conhecimento cada vez mais aprofundado de si próprio e o relacionamento solidário com os outros". (PACHECO, 2012, p. 152).

Quando definimos que a estrutura inicial do projeto se daria dessa maneira, passamos a intercalar as aulas nessa abordagem com as aulas que a professora supervisora ministrava, pois também prezávamos muito pelo crescimento que o observar poderia trazer para nossa formação inicial como docentes de uma língua estrangeira. A partir de um dado momento, no entanto, ela sugeriu que passássemos a utilizar todas as aulas para o nosso experimento. Ao termos a oportunidade de utilizar todas as aulas do ano para o desenvolvimento do projeto, decidimos dividir o número de aulas que seriam dadas pela quantidade de tópicos contidos no planejamento anual da disciplina para que tivéssemos uma base de quanto tempo, no máximo, um aluno poderia levar por tópico para chegar no final do ano e ter completado todo o programa decidido na reunião pedagógica pelos professores. Essa decisão foi feita tendo como objetivo trazer para a nossa prática em sala de aula dois dos pilares do projeto "Escola da Ponte" (PACHECO, 2012): primeiramente, a autonomia, pois os alunos teriam a liberdade de escolher qual tópico estudar em dado momento, mas, também, a responsabilidade de estar ciente de que todos os tópicos, como previstos pela equipe pedagógica no currículo, deveriam ser vistos até o final do ano. De acordo com Pacheco (2012).

Todos os conteúdos estão organizados em forma de listas de objetivos. As crianças lidam com objetivos o tempo todo. Não fazem nada que não seja 


\title{
Dossiê Especial: Experiências do PIBID na formação inicial e continuada de professores de línguas estrangeiras \\ HIBARINO \& NODARI (orgs) \\ Revista X, vol.1, 2015
}

para atingir um objetivo, tudo ganha sentido em função de objetivos a atingir. (PACHECO, 2012 p. 20).

O fato de os alunos poderem escolher o que querem aprender não lhes dá a opção pelo não trabalho. "Os alunos têm consciência disso e, por essa razão, planificam, quinzenalmente, o estudo de conteúdos associados a cada uma das áreas". (PACHECO, 2012, p. 130).

Para introduzir gradualmente a forma diferenciada de estudar Inglês, começamos com a aplicação de um questionário sobre múltiplas inteligências (com base em GARDNER, 1993) com o objetivo de criarmos uma base inicial sobre as características e preferências individuais do nosso público. Ao aplicarmos o questionário, nossa meta principal era conhecer melhor cada aluno, valorizando as suas diferenças e usando-as para prepararmos atividades que poderiam explorar seus diferentes potenciais. Assim, aproximaríamos a Língua Inglesa da rotina, contexto e interesses deles. Nas palavras de Howard Gardner:

\begin{abstract}
Prestar atenção ao aluno tal qual ele é; reconhecê-lo no que o torna único e irrepetível, recebendo-o na sua complexidade; tentar descobrir e valorizar a cultura de que é portador; ajudá-lo a descobrir-se e a ser ele próprio em equilibrada interação com os outros - são atitudes fundadoras do ato educativo e as únicas verdadeiramente indutoras da necessidade e do desejo de aprendizagem. (GARDNER, 1993, p. 152).
\end{abstract}

A importância de valorização dos diversos potenciais encontrados na sala de aula, não exclusivamente no ensino de Língua Inglesa, é mencionada por Howard Gardner, que defende que cada ser humano nasce com um vasto potencial de talentos ainda não moldado pela cultura, o que só começa a ocorrer por volta dos 5 anos. Segundo ele, alguns agentes envolvidos na educação falham ao não levar em conta os vários potenciais de cada indivíduo. Além disso, é comum que essas aptidões sejam reprimidas pelo conceito homogêneo que grande parte das escolas atribuem aos alunos. O ideal seria que a escola estivesse sempre preparada para diagnosticar e ajudar a desenvolver essas habilidades individuais, o que seria, nas palavras de Gardner, a sala de aula como "um programa de enriquecimento precoce, que começa a desenvolver habilidades intelectuais nos primeiros anos de vida de uma pessoa [e que] pode ter efeitos mensuráveis a longo prazo sobre as atitudes dos alunos e suas realizações" (GARDNER, 1993, p. 12). ${ }^{4}$

Em algumas situações, por exemplo, os alunos tem a intenção de falar, opinar,

\footnotetext{
${ }^{4}$ No original: "[...] a program of early enrichment which begins to develop intellectual skills in the first years of a person's life, can have measurable long-term effects on students attitudes and achievements." (GARDNER, 1993, p. 12).
} 


\section{Dossiê Especial: Experiências do PIBID na formação inicial e continuada de professores de línguas estrangeiras \\ HIBARINO \& NODARI (orgs) \\ Revista X, vol.1, 2015}

desenhar, etc., em sala de aula, mas são por vezes reprimidos seja para evitar a indisciplina ou para dar preferência à transmissão de conteúdo por parte do professor. Conforme Bohn:

O papel do mediador é o da autoridade em oposição à conversação, o diálogo, a linguagem dialógica (Bakhtin, 1999). O papel do mediador pressupõe que o objeto observado já foi avaliado, definido, a sua realidade, portanto, percebida e descrita no texto pedagógico e transmitida no discurso do professor. $\mathrm{O}$ conhecimento assim percebido não permite o diálogo na sala de aula, não há espaço para a linguagem de compreensão. Há sim lugar para o discurso autoritário (Orlandi, 1996, 2000), para a inteligibilidade de arquivos prontos, também autoritários, de verdades estabelecidas, homogêneas, lineares, disciplinares, arquivos a serem memorizados e repetidos pelos alunos nas avaliações. (BOHN, 2003, p. 117).

Situações como essas podem levar os professores a deixarem de lado surpreendentes possibilidades, e o potencial natural das crianças passa a ser diminuído pela ausência de incentivo. Estávamos dispostas a mudar essa realidade ajudando a construir um ambiente “onde o objeto pronto, acabado, estruturado é substituído pelo movimento, pelo inacabado, por movimentos estruturantes" (Bohn, 2003, p. 117). Somente a partir dessa alteração na rotina de trabalhos acreditávamos que seria possível potencializar o uso da língua inglesa como um meio para incentivá-los a construir seu próprio conhecimento. Tentamos assegurar, dentro das possibilidades postas pelo contexto, os recursos necessários para o acesso a essas informações (como fichas individuais de desempenho, autoavaliações, etc).

Logo no início do projeto, tendo em vista que todos desejavam ter mais liberdade, trouxemos do projeto "Fazer a Ponte" (PACHECO, 2012) a ideia de realizar uma assembleia para que os alunos pudessem expressar suas opiniões sobre o que é liberdade, e como deveria ser o relacionamento em sala de aula. Perguntamos o que deveríamos fazer para que o outro respeitasse a nossa vontade e vice-versa e discutimos que regras deveriam ser colocadas em prática durante as aulas para que todos tivessem esse direito garantido. Essa atividade foi primordial para que todos refletissem sobre seus papéis como sujeitos ativos na criação de seus direitos e deveres. A discussão foi realizada na língua materna, mas rendeu um trabalho escrito em língua inglesa onde foram registradas as regras que eles mesmos elaboraram.

O tópico 1 do artigo 12 do Regulamento interno do Projeto "Fazer a Ponte", sobre a Assembleia de Escola, diz:

Enquanto dispositivo de intervenção direta, a Assembleia de Escola é a estrutura de organização educativa que proporciona e garante a participação 


\section{Dossiê Especial: Experiências do PIBID na formação inicial e continuada de professores de línguas estrangeiras \\ HIBARINO \& NODARI (orgs) \\ Revista X, vol.1, 2015}

democrática dos alunos na tomada de decisões que dizem respeito à organização e ao funcionamento da Escola. (PACHECO, 2012, p. 167).

Alves (2012), ao descrever o que viu durante sua visita à Escola da Ponte, relata:

Para exercer a solidariedade é necessário compreendê-la, vivê-la em todo e qualquer momento. Na Ponte, cada criança age como participante solidário de um projeto de preparação para a cidadania no exercício da cidadania. Foi por isso que se constituiu, há cerca de 20 anos, a Assembleia. É por aí que passa a participação das crianças na organização interna da sua escola. Os miúdos sabem que "a Assembleia é uma coisa importante", "que os alunos e os professores reúnem-se e discutem juntos os problemas da escola", que "aprendemos a respeitar regras e a respeitar-nos uns aos outros e a decidir o que é melhor para todos". (ALVES, 2012, p. 111).

No decorrer da primeira aula perguntamos que tipos de atividades os alunos achavam interessantes e que materiais gostariam de ter sempre disponíveis em sala de aula. Foi sugerido por eles que tanto o que haviam aprendido na assembleia quando o que viriam a aprender fosse exposto na forma de debate, jornal, desenhos, entrevista, música, canto, fotografia, poesia, culinária, horta comunitária, apresentação teatral. Outra sugestão foi a de que aqueles que quisessem poderiam usar tecnologias como ferramentas para suas pesquisas e projetos, além de utilizar conteúdo de outras matérias para estudar em inglês, como, por exemplo, geografia, história e ciências.

Após essa fase de debates e construção conjunta, partimos para uma terceira fase de atividades, que envolvia a interação entre os pares para a confecção dos cartazes com as regras de bom convívio na sala de aula. Ao realizarmos a assembleia onde foram definidas as regras a serem seguidas pela turma, percebemos que precisaríamos de um espaço maior que permitisse que os alunos ficassem reunidos em grupos de 5 ou 6 , para fazerem os cartazes. $\mathrm{O}$ espaço disponível para isso na escola foi o auditório.

Propusemos várias funções as quais os alunos poderiam desempenhar individualmente dentro de cada grupo (pesquisador, recortador, anotador, organizador, ilustrador, porta-voz, etc.). Seguimos esse procedimento tendo como certo que o se sentir útil é fator motivacional no trabalho em grupo. Além disso, ao darmos aos alunos a oportunidade de escolherem suas funções, poderíamos conhecer as suas preferências e, consequentemente, percebermos um potencial a ser explorado em futuras atividades. Nesse momento, tínhamos também como objetivo trazer para a prática em sala de aula outro pilar do projeto "Fazer a Ponte" (PACHECO, 2012): a cooperação.

Assim, tentamos delegar funções para cada membro de cada grupo, de acordo com a 
Dossiê Especial: Experiências do PIBID na formação inicial e continuada de professores de línguas estrangeiras

HIBARINO \& NODARI (orgs)

Revista X, vol.1, 2015

opinião do aluno, deixando claro que cada um tinha uma função no processo de elaboração do cartaz e que o grupo dependia de cada um exercendo seu papel, pois tanto a cooperação quanto a responsabilidade eram importantes. Depois das regras e objetivos terem sido expostos para professores e alunos, fomos para o auditório da escola, local mais amplo e disposto de móveis mais apropriados para a condução da proposta. Distribuímos, então, recursos para que o trabalho pudesse ser realizado (tais como tesoura, revistas, cartolinas, etc.).

Trazer para a sala de aula a ideia de conflito como algo positivo (JORDÃO, 2007) não foi fácil já que, geralmente, as tarefas realizadas em colaboração são estimulantes e representam um desafio, porém ao juntar recursos e ao lidar com as discordâncias de opinião que vão surgindo, os grupos desenvolvem um produto mais aprofundado do que se cada indivíduo trabalhasse sozinho. É a proposta de estímulo aos sujeitos críticos que, de acordo com Jordão, “devem ser capazes de examinar as informações e as implicações das diferentes formas de pensar e agir, pressupondo realidades construídas culturalmente nas relações que estabelecem entre diferentes visões de mundo.” (JORDÃO, 2007, p. 22).

É fundamental atribuir tarefas que encorajem o envolvimento, a interdependência e a divisão justa do trabalho para que todos os membros do grupo se sintam pessoalmente responsáveis e compreendam que o seu sucesso individual depende do sucesso do grupo e vice-versa. Nas palavras de Rubem Alves:

Tudo o que acontece na Escola da Ponte é, antes de mais nada, "educação na cidadania". Quando as crianças pesquisam, investigam e aprendem em grupo e as "mais dotadas" se responsabilizam pelo acompanhamento e o apoio à aprendizagem das "menos dotadas" [...] Quando as crianças, desde a iniciação, habituam-se a pedir a palavra para falar e habituam-se a ouvir os outros em silêncio e com a devida atenção [...] a educação na cidadania é o próprio respirar e sentir da comunidade, não é uma enxertia de conceitos pretensamente civilizadores numa cabeça cujo corpo está em permanente e agressiva concorrência com os outros. (ALVES, 2012, p. 16-17).

Estipulamos uma estimativa de tempo para a atividade, porém percebemos que os grupos apresentaram diferentes ritmos. O que foi observado serviu para a preparação de futuras atividades, como, por exemplo, dispor alunos de saberes diferentes no mesmo grupo como uma estratégia facilitadora para o processo de aprendizagem. Para tanto, consideramos desde o início a necessidade de realizar um estudo diagnóstico individual.

Ao final desse primeiro momento de trabalho em grupo, propusemos aos alunos que 
Dossiê Especial: Experiências do PIBID na formação inicial e continuada de professores de

línguas estrangeiras

HIBARINO \& NODARI (orgs)

Revista X, vol.1, 2015

preenchessem uma ficha de autoavaliação (FIGURA 1). Esse também se caracterizou o primeiro de muitos momentos em que utilizaríamos essa atividade no projeto, considerando que a autoavaliação está totalmente presente no processo de autonomia que pretendíamos ajudá-los a desenvolver. Nesse experimento estaríamos trabalhando somente por um ano, mas na Escola da Ponte: "[s]ão anos de prática cotidiana de autoavaliação. No final dos seus anos de escola, isto está de tal forma internalizado que passa a ser a sua maneira natural de aprender, sempre se autoavaliando, a cada passo." (ALVES, 2012, p. 20).

Os alunos reagiram muito bem à autoavaliação (FIGURA 1), não havendo recusa em preencher todos os quesitos solicitados que foram aplicados e respondidos na língua materna, pois visavam um autoconhecimento em relação ao próprio aprendizado. Os alunos demonstraram ter consciência do papel que desempenhavam, sendo ele bom ou ruim na visão deles. A maioria deles também sugeriu em que pontos seria ideal que melhorassem. Interpretamos esse resultado inicial de forma muito positiva, pois percebemos que os alunos tinham muita consciência de suas atitudes, ou seja, estavam capacitados para iniciar projetos nos quais passassem a se autoavaliar de forma mais contínua.

AVALIAÇÃO PESSOAL - $1^{\text {a }}$ atividade em grupo ALUNO:

\begin{tabular}{|l|}
\hline 1)Participei ativamente das atividades do grupo para realização do trabalho? Como? \\
\hline 2) Tratei com respeito meus colegas e professores durante a realização do trabalho? \\
\hline 3) Qual foi o aprendizado significativo que tive com essa atividade? \\
\hline 4) O que preciso melhorar?
\end{tabular}

FIGURA 1 Ficha de avaliação pessoal da primeira atividade em grupo.

A partir daí disponibilizaríamos todos os recursos ao nosso alcance para que eles pudessem assumir a responsabilidade por sua aprendizagem. Essa delegação de algumas tarefas para o aluno foi um dos pontos principais do projeto, pois a autonomia para que se autoavaliassem traria a eles a sensação de serem responsáveis por seus estudos, e a individualidade de cada um ficaria mais evidente tanto para ele quanto para nós. O feedback auxiliaria no desenvolvimento de avaliações mais formais, que também fizeram parte da avaliação como um todo durante o projeto. Conforme Pacheco (2012):

Se nós pensarmos na nossa vida de "adultos", poderemos verificar facilmente que nos autoavaliamos centenas de vezes. Por outro lado, sempre que somos avaliados por outros, temos a sensação de que algo não correu muito bem, que o processo não foi totalmente transparente, que demos prioridade a outros aspectos. (PACHECO, 2012, p. 65).

Como proposta para melhorar o sujeito, o autor sugere que: 


\section{Dossiê Especial: Experiências do PIBID na formação inicial e continuada de professores de línguas estrangeiras \\ HIBARINO \& NODARI (orgs) \\ Revista X, vol.1, 2015}

[...] a escola deve fomentar o processo autoavaliativo (quer para alunos quer para professores), um espaço de discussão e avaliação em conjunto (com pares), deve fomentar o diálogo avaliativo entre professor e aluno, no sentido de serem melhorados aspectos do processo ensino-aprendizagem.( PACHECO, 2012, p. 141).

Nas aulas posteriores a assembleia, iniciamos as atividades de Língua Inglesa com os alunos. Apresentamos os tópicos que deveriam ser estudados no decorrer do ano e a forma como trabalhariam esses tópicos, já que poderiam escolher aquele que gostariam de aprender naquele momento e teriam um tempo estipulado para desenvolvê-lo a partir das atividades que traríamos, do que produziriam em sala de aula e, também, do que trariam de casa. Com base no aporte teórico de Pacheco (2012), além de nossa experiência como estudantes de escola pública, pretendíamos trazer elementos que propiciassem uma intensificação no desenvolvimento intelectual dos alunos, e uma aprendizagem significativa do idioma.

Através da descrição de Rubem Alves (2012), pudemos obter detalhes que nos ajudariam na decisão por adequar ideias da Escola da Ponte a nossos planos para o projeto do momento posterior a assembleia em diante:

Parece simples e até romântico? Parece, mas funciona. É ver, por exemplo, como as crianças elaboram quinzenalmente os seus planos de trabalho e como se propõem à avaliação, quando consideram ter atingido os objetivos de aprendizagem que se impuseram; é ver como as crianças organizam os seus roteiros de consulta bibliográfica e como operacionalizam as suas pesquisas; é ver como as crianças se empenham, responsavelmente, na concepção, na planificação, na concretização e na avaliação dos projetos; é ver como as crianças, semanalmente, elaboram, discutem e aprovam as atas da assembleia; é ver como as crianças, nos relatórios e comunicações, dão conta das suas "descobertas"; é ver como as crianças identificam e verbalizam as suas dificuldades de aprendizagem e como se disponibilizam solidariamente a ajudar os colegas que precisam e reclamam apoio; é ver como as crianças descrevem e falam da sua escola aos visitantes... (ALVES, 2012, p. 36).

Rubem Alves afirma ter conversado diretamente com alunos da Escola da Ponte para compreender seus mecanismos pedagógicos. Em um determinado trecho, ele relata ter sido guiado por uma aluna aparentando ter cerca de 10 anos de idade. Conforme o autor, ela resumiu sua rotina geral da seguinte forma:

Aprendemos assim: formamos pequenos grupos com interesse comum por assunto, reunimo-nos com uma professora e ela, conosco, estabelece um programa de trabalho de 15 dias, dando-nos orientação sobre o que 
Dossiê Especial: Experiências do PIBID na formação inicial e continuada de professores de línguas estrangeiras

HIBARINO \& NODARI (orgs)

\section{Revista X, vol.1, 2015}

deveremos pesquisar e os locais onde pesquisar. Usamos muito os recursos da Internet. Ao final dos 15 dias nos reunimos de novo e avaliamos o que aprendemos. Se o que aprendemos foi adequado, aquele grupo se dissolve, forma-se um outro para estudar outro assunto. (Alves, 2012, p. 43)

Procuramos seguir algumas ideias semelhantes às descritas acima considerando sempre as limitações que encontrávamos, pois precisávamos reduzir a abordagem a uma única turma e disciplina.

Ao final da primeira aula, os alunos tiveram a oportunidade de conhecer todos os tópicos que deveriam ser trabalhados durante o ano letivo, segundo a proposta pedagógica, e escolher o tópico inicial (FIGURA 2).

\begin{tabular}{|l|l|}
\hline \begin{tabular}{l|l|} 
Cumprimentos \\
Responder \\
perguntas básicas
\end{tabular} & Cores \\
\hline Números (1-20) & Mesissões do ano \\
\hline Números (21-110) & Estrangeirismos \\
\hline Esportes & Vestuário \\
\hline Pá́mes & Números ordinais \\
\hline Árvore genealógica & Dias da semana \\
& Material escolar \\
\hline Formas & \\
\hline
\end{tabular}

FIGURA 2: Tópicos do planejamento anual- $6^{\circ}$ Ano.

Estipulamos também uma meta de aproximadamente 15 dias para a finalização de cada tópico (FIGURA 3), por julgar que este tempo seria adequado para a pesquisa e aprofundamento do assunto pesquisado e por julgar compatível com a faixa etária dos alunos. 
Dossiê Especial: Experiências do PIBID na formação inicial e continuada de professores de línguas estrangeiras

HIBARINO \& NODARI (orgs)

Revista X, vol.1, 2015

NOME do ALUNO:

Atividades que fareicom toda a Turma da $6 !$ A

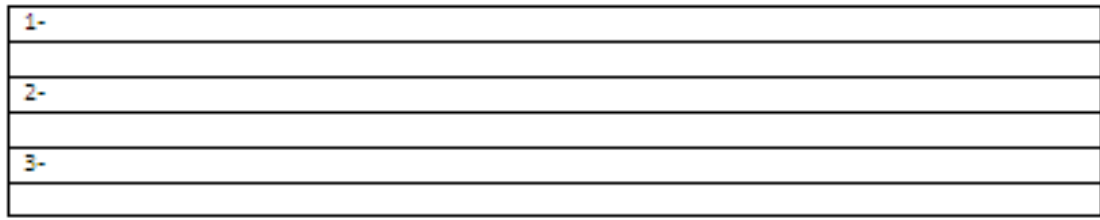

Sugestôes que eu gostaria de apresentar:

\begin{tabular}{|l|}
\hline Acho bom: \\
\hline \\
\hline Acho ruim: \\
\hline \\
\hline
\end{tabular}

Meu grupo de responsabilidade é: ?

\begin{tabular}{|l|}
\hline Eu já sei: \\
\hline \\
\hline Posso ajudar: \\
\hline \\
\hline Preciso de ajuda: \\
\hline
\end{tabular}

Projeto de Pesquisa: o que vou fazer nessa quinzena. Que tema quero pesquisar.

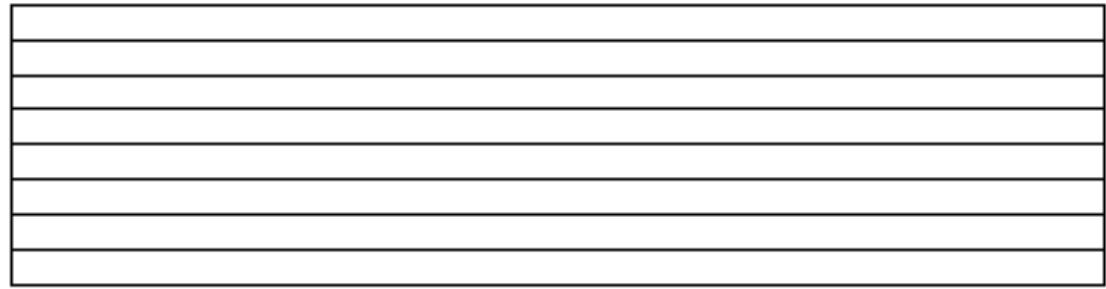

FIGURA 3: Planejamento individual para a quinzena.

Não fomos muito rigorosas na busca por essa meta quinzenal devido à fase de adaptação pela qual os alunos teriam que passar diante da mudança em suas rotinas habituais em sala de aula. Além disso, estávamos conscientes que existiriam vários ritmos de progressão individual e, ao longo da aplicação do projeto, pudemos comprovar que essa seria uma realidade com a qual deveríamos aprender a lidar, e respeitar ao longo de todo o ano.

Detectamos que alguns alunos apresentavam, por exemplo, dificuldades de interação e mesmo comportamento agressivo. Tivemos, inclusive, um aluno transferido para essa turma por fazer parte de um grupo considerado extremamente indisciplinado. Esse aluno, por vezes, ser recusava a interagir de forma amistosa com os colegas durante as primeiras aulas, assim como realizar pesquisas em conjunto. Não foi difícil percebermos que carregava, talvez dentre outros fatores psicológicos, certa dose de falta de autoestima com relação à própria 


\section{Dossiê Especial: Experiências do PIBID na formação inicial e continuada de professores de línguas estrangeiras \\ HIBARINO \& NODARI (orgs) \\ Revista X, vol.1, 2015}

capacidade de aprender. Esta era externada por um padrão de comportamento de rejeição do que lhe era proposto e busca de atenção através de brigas com os meninos e flertes com as meninas. Trabalhamos sua motivação buscando mostrar-lhe suas aptidões, e notamos que ele passou aos poucos a canalizar sua energia para outros aspectos da aula, como a pesquisa e a boa convivência. Acreditamos que esse tenha sido um bom exemplo de um indivíduo que começou a aprender a ser, para então passar a outras fases necessárias de sua educação. Não estamos aqui tentando propor um significado para a palavra ser, e sim entender aquilo que traz a cada um de nós motivação para encaminhar nossas vidas de maneira positiva.

Durante o planejamento e os diálogos atentamos para o fato de que deveriam existir organização e etapas em forma de roteiros preparados por nós bolsistas para facilitar a realização das tarefas por parte dos alunos. Além disso, visualizávamos que a Língua Inglesa era ferramenta para o desenvolvimento das potencialidades dos alunos, ou seja, não era o único meio e fim da aprendizagem. Por exemplo, em uma determinada atividade, quando usávamos um vídeo curto sobre reciclagem, o aluno aprendia algumas expressões na língua Inglesa, como "You will need scissor and glue", mas ele aprendia também sobre como reutilizar material reciclado em artesanato, e que o lixo é um problema mundial do qual todos somos responsáveis. Além disso, esse aluno reconhece em outra criança que fala uma Língua diferente da dele, em um outro país, atividades similares como a de construir seu próprio brinquedo. Dentro dessa abordagem, podemos estabelecer um laço também entre a solidariedade, autoavaliação, democraticidade e consciência de cidadania, propostos pela Escola da Ponte com o conceito de letramento crítico explanado por Clarissa Jordão:

Se entendemos que a língua constrói sentidos, então uma língua estrangeira se apresenta como um espaço de construção de sentidos outros, que ampliam e alteram os processos de construção de sentidos da primeira língua. Uma vez que os sentidos se constroem na língua, com a língua e pela língua (assim como a democracia!), então aprender línguas é aprender procedimentos interpretativos. $\mathrm{E}$ aprender procedimentos interpretativos criticamente é aprender a exercer a cidadania. (JORDÃO, 2007, p. 28).

Através da construção de sentidos é que se torna possível conhecer o outro e a si próprio, por isso é primordial que haja a interação entre os pares. É diante desse contato com o outro que se percebe o diferente, e somente quando se compreende que não é possível fazer o outro igual a si, nem se transformar no outro que é possível desenvolver a solidariedade necessária para ajudar e ser ajudado. A democraticidade anda na mesma linha, a partir do 


\section{Dossiê Especial: Experiências do PIBID na formação inicial e continuada de professores de línguas estrangeiras \\ HIBARINO \& NODARI (orgs) \\ Revista X, vol.1, 2015}

momento em que se percebe que o outro não precisa pensar como eu, e que em alguns momentos tenho que ceder para o bem comum, não precisando para isso mudar o jeito de pensar. A autoavaliação é uma das maneiras de se conhecer, de tomar as rédeas de si e do seu próprio conhecimento, de estar constantemente buscando se construir.

Cada tópico escolhido pelo aluno deveria seguir uma sequência de passos determinados pelas bolsistas, sendo que cada uma das três se tornaria a "tutora" de 10 alunos para acompanhar de perto suas produções e desempenho. Essa divisão visava uma maior disponibilidade para que os alunos tirassem, individualmente, as suas dúvidas e fosse possível ajudá-los a reconhecer e desenvolver as suas potencialidades. Como propõe a abordagem da Escola da Ponte, os alunos escolhem individualmente um tópico para pesquisar, sendo o educador um facilitador do conhecimento e não detentor único dele; o professor se torna uma ponte entre o aluno e o conhecimento a ser adquirido. Assim, no projeto Caleidoscópio, os alunos tinham a opção de escolher o tópico a ser estudado naquele momento e poderiam se juntar a outros por afinidades tanto de conteúdos quanto interpessoais. Disponibilizamos diversos recursos para pesquisa, além do livro didático, tais como: dicionário ilustrado, laptop, vídeos, graded readers, gibis, jornais, revistas, etc. Também foram disponibilizados materiais como: tesoura, cola, cartolina, canetinha, lápis de cor, glitter, régua, entre outros, os quais foram usados para a realização das atividades em sala de aula.

Preparamos uma ficha onde eles mesmos deveriam anotar o tema que decidiram pesquisar e ao final realizariam a auto avaliação de seu rendimento, (FIGURA 3), mas como estávamos trabalhando com alunos do $6^{\circ}$ ano, com idades entre 11 e 12 anos, essa ficha não foi tão eficiente como esperávamos. Por isso, pensamos em criar algo que os ajudasse na visualização dos tópicos que haviam produzido. Surgiu então a ideia de criarmos uma árvore do conhecimento, que precisaria ser alimentada para crescer. A cada tópico concluído o aluno deveria colar uma folha no galho da "Knowledge tree" (FIGURA 4). Os alunos se envolveram muito nessa atividade de autoavaliação, pois ainda estão em uma faixa etária em que gostam de colorir e recortar. Cada folhinha de árvore que colassem levaria o nome do tópico finalizado. Considerando que esta atividade foi desenvolvida ao longo do segundo semestre, os alunos puderam perceber o seu progresso na aprendizagem e essa percepção serviu como fator motivacional para a realização das atividades subsequentes. 


\section{Dossiê Especial: Experiências do PIBID na formação inicial e continuada de professores de línguas estrangeiras \\ HIBARINO \& NODARI (orgs)}

Revista X, vol.1, 2015

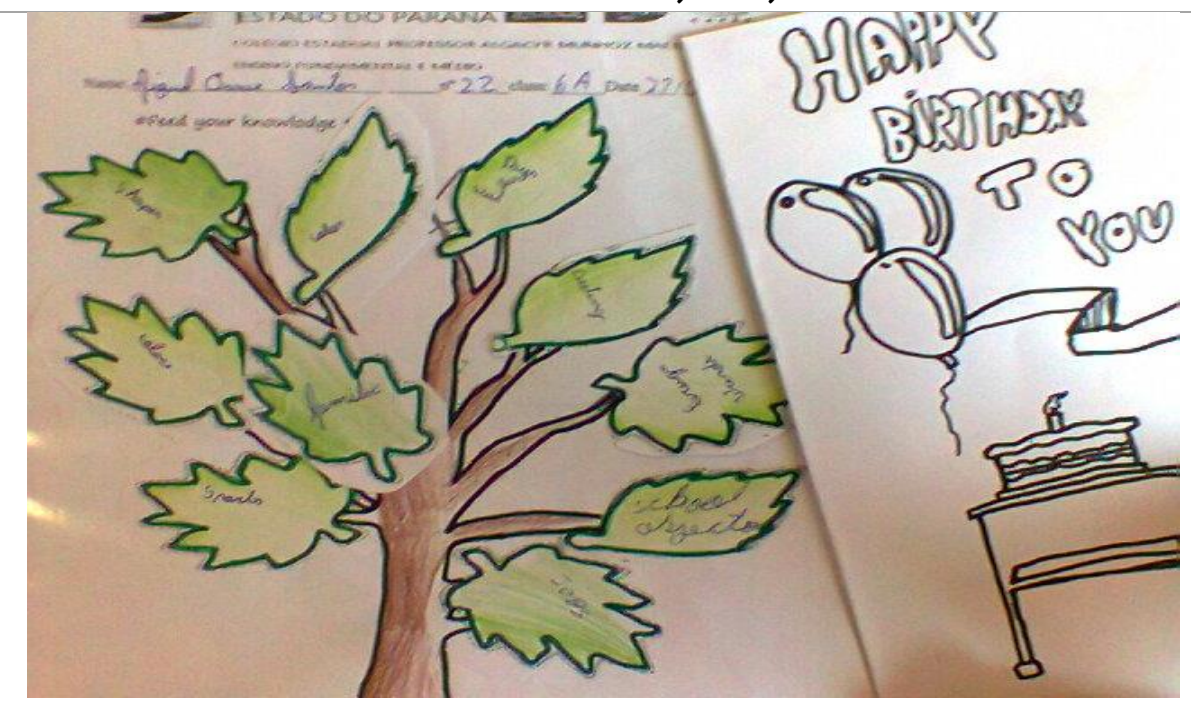

FIGURA 4: "Knowledge tree"

Observamos que a maioria dos alunos não viam a responsabilidade de estudar como algo bom e importante em suas vidas. Concebiam as suas atividades escolares como algo enfadonho e desagradável que tinham a obrigação de fazer. Com nossa proposta buscamos ajudá-los a se identificarem como sujeitos de seu próprio destino. Passou a ser muito importante para nós, enquanto professoras em formação inicial, orientá-los em suas atividades, preservando suas próprias experiências na busca do aprendizado. Para isso nos baseamos em um dos pressupostos do letramento crítico que consiste em desconstruir uma ideia pré-estabelecida, no caso desses alunos, de que estudar inglês era chato e difícil, mostrando que havia formas de aprender que podiam ser interessantes e divertidas. Assim que explicamos como seriam as aulas e estabelecemos as regras, os alunos rapidamente compreenderam e passaram a interagir para realizá-las. Em alguns casos o aluno só precisava de um elogio para continuar desenvolvendo os itens de seu tópico. Já em outros, era necessário um direcionamento mais incisivo na forma de estudar. Nesse aspecto podemos considerar que houve uma mudança substancial de comportamento e engajamento.

\section{Considerações finais}

Um fator que contribuiu para que alguns alunos apresentassem mais dificuldade para compreender e se adaptar a nossa proposta deveu-se ao fato desta abordagem se constituir apenas como um recorte de tudo que apreciamos como o ideal a ser adotado no ambiente escolar, mas não acontecer nas demais disciplinas e turmas da referida escola. Isso equivale a 


\section{Dossiê Especial: Experiências do PIBID na formação inicial e continuada de professores de línguas estrangeiras \\ HIBARINO \& NODARI (orgs) \\ Revista X, vol.1, 2015}

dizer que algumas práticas precisam de rotina para serem acomodadas na compreensão do ser humano, e a alternância de abordagens a que os alunos se viram submetidos os deixou um tanto confusos. Houve uma ocasião em que não pudemos estar presentes em uma semana na escola, e quando voltamos na semana seguinte os alunos apresentaram comportamento inquieto, conversavam e se movimentavam muito durante a aula. Ao analisar esta situação, a comparamos com as necessidades fisiológicas por comida, água, oxigênio, etc. Se alguém tem a satisfação dessas necessidades restrita, após certo tempo a necessidade passa a ser gritante, e quando o indivíduo volta a ter acesso a essas fontes de satisfação, seu corpo as consome de imediato e descontroladamente. No exemplo dos alunos, cremos que esse elemento fosse a interação com os colegas que era liberada nas aulas de Inglês, uma vez que pudemos observar através das reuniões pedagógicas trimestrais, das quais participamos como ouvintes desde o começo do ano, que a maioria dos professores não tinha por hábito dar liberdade de escolha para os alunos dentro da sala, justificado muitas vezes pela falta de recursos materiais ou o grande número de alunos por turma.

Outro fator que consideramos conflituoso durante o desenvolvimento se deve a prática da fala em língua inglesa. Através dessa abordagem encontramos maneiras de trabalhar a compreensão auditiva e escrita, assim como a produção escrita, mas a produção oral não estava sendo trabalhada na mesma proporção. Isso aconteceu devido à limitação de tempo para atender alunos individualmente e pelo ruído causado tanto pela constante interação dos grupos quanto por fatores externos. Com o objetivo de contemplar, ainda que superficialmente a habilidade da produção oral, elaboramos uma atividade na qual eles deveriam, ao final, reproduzir oralmente um texto curto, preferencialmente na forma de um diálogo.

Uma opção que encontramos foi a proposta de repetição como lição de casa. Considerando o fundamento de autonomia que buscamos desenvolver nos alunos, esperamos que tenham descoberto sobre suas capacidades de aprender sozinhos, como ao ouvir o CD de Língua Inglesa do livro. Essa última sugestão não funcionou muito bem em sala de aula, pois apenas poucos alunos se propuseram a ouvir, talvez até por não terem onde e, nós, tutoras não tínhamos tempo hábil para potencializar essas habilidades individualmente durante as aulas.

Outro elemento que divergiu um pouco da intenção inicial do projeto foram as assembleias, nas quais os alunos tiveram várias oportunidades para manifestarem suas opiniões. Como relatado anteriormente, conseguimos colocar essa ideia em prática algumas vezes. Contudo, ao final do ano, alguns aspectos limitaram o nosso planejamento, tais como mudanças de horários e datas para a condução destas. 


\section{Dossiê Especial: Experiências do PIBID na formação inicial e continuada de professores de línguas estrangeiras \\ HIBARINO \& NODARI (orgs) \\ Revista X, vol.1, 2015}

Mas não foram somente as assembleias que foram prejudicadas por esses fatores. Não tínhamos levado em conta na preparação do planejamento anual a realidade da administração organizacional de algumas escolas públicas, que muitas vezes carecem de comunicação com os envolvidos na rotina escolar. Isso nos trouxe certa frustração e nos colocou em situações inesperadas durante vários momentos do ano. Postergamos por essa razão, atividades planejadas conforme o calendário escolar e limitamos nosso cronograma de atividades. Alguns tópicos e planejamentos bem elaborados ficaram comprometidos diante da mudança de planos para eventos não informados com antecedência (como passeios, suspensão de aulas para assistir a jogos de futebol ${ }^{5}$, semana de jogos escolares, teatros, etc). Se tais eventos nos tivessem sido informados em tempo hábil, poderíamos buscar aproveitá-los pedagogicamente, o que não aconteceu, ao menos em nossa disciplina. Esses percalços nos abriram os olhos para o fato de que quando um docente se envolve com a escola pública, deve se envolver por inteiro. Estávamos na escola na qualidade de bolsistas de iniciação à docência e, portanto, com presença regular, mas não integral como é a de professores regulares.

Após o trabalho durante o ano letivo de 2013 com a turma de $6^{\circ}$ ano, consideramos que nossos objetivos iniciais de desenvolver espaços para autonomia, solidariedade, democraticidade e cooperação por parte dos alunos do $6^{\circ}$ ano foram atingidos. Como constava em nossa proposta inicial, foi respeitado o tempo de cada aluno para a compreensão e realização das tarefas. $\mathrm{O}$ aproveitamento dessa turma que nos foi entregue como sendo complicada e indisciplinada foi mais que satisfatório. Entendemos ainda que mesmo tendo situações de conflito, essas não impediram o desenvolvimento dos nossos objetivos iniciais. Aliás, podemos afirmar que esses conflitos, foram úteis como prática de letramento crítico, na acepção do que este conceito representa conforme JORDÃO (2007) pois, tanto para os bolsistas quanto para os alunos, foi uma oportunidade de discordar, discutir, rever conceitos, buscando sempre entrar em consenso para atingir um objetivo comum.

No quesito autonomia, todos os alunos sabiam onde encontrar seu material sem ajuda do professor depois de certo tempo. Além disso, passaram a cooperar com seus colegas em muitas situações, trocando conhecimentos sobre o que já haviam aprendido, e passaram a interagir e se conhecer melhor. O padrão indiferente ou agressivo de alguns alunos foi dando lugar ao interesse e a harmonia. Os alunos tinham liberdade para conversar durante as aulas, e se sentiam muito animados diante disso. Aos poucos aprenderam a conhecer seu próprio potencial, na prática de autoavaliação. Podemos afirmar que todos tiveram seus ritmos de

\footnotetext{
${ }^{5}$ Lembrando que as atividades foram realizadas no ano de 2014, quando a Copa foi sediada no Brasil.
} 
Dossiê Especial: Experiências do PIBID na formação inicial e continuada de professores de

línguas estrangeiras

HIBARINO \& NODARI (orgs)

Revista X, vol.1, 2015

adaptação e progressão respeitados.

Este texto, porém, não tem a pretensão de defender a abordagem que usamos como sendo a melhor para escolas públicas. Contudo, acreditamos que essa abordagem poderia ser adaptada a diversos contextos educacionais, pois proporciona abertura para as tendências individuais dos alunos, ao mesmo tempo em que os incentiva a serem responsáveis por seu próprio aprendizado, ou seja, não é fechada em si mesma. Sendo assim, se o perfil do aluno é mais compatível com aulas expositivas, por terem memória auditiva aguçada, por exemplo, ele tem o direito de ter essas aulas, mas se o aluno tem mais facilidade para aprender com estímulos audiovisuais ou pesquisando, compete à escola, através do professor, diagnosticar e proporcionar o acesso a essas ferramentas.

Acreditamos que esse modelo experimental rendeu resultados positivos. No entanto, deve-se levar em consideração que para que essa abordagem seja eficiente o número de alunos em sala de aula precisaria diminuir e os recursos, inclusive tecnológicos, precisariam melhorar consideravelmente nas escolas estaduais, o que mostra que esse tipo de trabalho talvez não possa ser desenvolvido em qualquer contexto educacional.

\section{Agradecimento}

Agradecemos à CAPES pela concessão das bolsas PIBID que possibilitaram a realização desta pesquisa.

\section{Referências}

ALVES, R.. A escola com que sempre sonhei sem imaginar que pudesse existir. Campinas, SP: Papirus, 2012.

BOHN, H.. Maneiras Inovadoras de Ensinar e Aprender. Pelotas: Edicat, 2000.

FARACO, C. A.. Linguagem \& Diálogo: as ideias linguísticas do círculo de Bakhtin. $1^{\mathrm{a}}$ ed. Curitiba: Criar edições, v1, 2003, Pp.13-43.

GARDNER, H.. Frames of Mind. The theory of Multiple Intelligences. New York, Basic Books, 1993.

GARDNER, H.. Quadros da mente. Teoria das inteligências múltiplas. New York, Basic Books, 1993.

JORDÃO, C. M. "As lentes do discurso: letramento e criticidade no mundo digital". Trabalhos em Linguística Aplicada,v.1, n.46,p. 19-29, Jan./Jun.2007.

PACHECO, J.. A avaliação da aprendizagem na Escola da Ponte. Rio de Janeiro: Wak Editora, 2012. 